\title{
ESTUDIO SEMÁNTICO-MORFOLÓGICO DIACRÓNICO DEL CASO DATIVO EN LA LENGUA CHECA ${ }^{1}$
}

\author{
ENRIQUe GUTIÉRREZ RUBIO
}

\section{RESUMEN}

El presente estudio semántico-morfológico pone en relación dos categorías, la datividad y la animación (o animicidad), a lo largo de las principales etapas de desarrollo de la lengua checa, de modo que muestre cuál ha sido la relación entre la categoría de animación y la doble posibilidad desinencial en el dativo singular masculino -ovi y $-u /-i$ a través de la análisis de la jerarquía de animación. El estudio se centra en cuatro textos checos -Crónica de Dalimil, Biblia de Kralice, La abuela y Trenes rigurosamente vigilados- y en un texto en antiguo eslavo, el Codex Marianus.

Palabras clave: dativo, animación, lingüística diacrónica, lengua checa, antiguo eslavo.

\section{ABSTRACT}

The aim of this semantic-morphological study is to understand and to show the relationship between the category of animacy and the endings -ovi and $-u /-i$ through the historical development of the Czech language from the first texts until the contemporary written Czech. The works that compose the corpus of our research are: Chronicle of Dalimil, Bible of Kralice, The Grandmother and Closely watched trains. To the analysis of the four Czech texts that form our corpus we added a fifth text in Old Church Slavonic, the Codex Marianus.

Key Words: dative, animacy, diachronic linguistics, Czech language, Old Church Slavonic.

\section{INTRODUCCIÓN}

Este artículo pretende estudiar, desde una perspectiva diacrónica, la relación entre dos categorías gramaticales, la datividad y la animación (o animicidad), presentes ambas en la lengua checa, ampliamente co-

\footnotetext{
${ }^{1}$ En su gran mayoría este artículo está extraído de mi tesis doctoral inédita: Estudio diacrónico del caso dativo en la lengua checa. A la investigación de carácter semántico-morfológico que se recoge aquí hay que añadir una semántico-funcional desde la perspectiva de la lingüística congnitiva y que aún está pendiente de su publicación.
} 
nocidas y relativamente bien estudiadas por separado, pero cuya relación no había sido analizada de un modo sistemático, por lo que no existían, hasta hoy, datos exactos sobre ésta a lo largo del desarrollo de las distintas etapas de la lengua checa.

Ya desde los primeros textos eslavos se hace patente una clara propensión a usar la doble desinencia de dativo singular $-u$ /-ovi para los sustantivos masculinos. Lo que resulta más interesante para nuestros propósitos es que la elección entre ambas formas por parte de los escribas no responde a un fenómeno arbitrario, sino que se observa una tendencia a que los sustantivos animados presenten la desinencia -ovi, frente a los inanimados que documentan con mayor frecuencia la desinencia $-u$.

Mediante este análisis pretendemos mostrar cuál ha sido la relación entre esta doble posibilidad desinencial en el dativo singular masculino y la categoría de animación a lo largo del desarrollo de la lengua checa. Para llevar a cabo la presente investigación hemos distribuido los sustantivos según una jerarquía de animación, que tiene como precedente metodológico otra de características muy similares realizada por Huntley 1993 en la que se relaciona la categoría de animación con el sincretismo genitivo-acusativo en antiguo eslavo.

El corpus empleado en el análisis consiste en cuatro textos especialmente representativos de otros tantos momentos relevantes en la historia de la lengua checa. El más antiguo, símbolo del periodo más arcaico de la lengua checa, denominada checo antiguo, es una crónica medieval conocida generalmente como Dalimilova kronika 'La crónica de Dalimil'. El segundo texto de nuestro corpus representa al denominado checo medio y se trata de la traducción que realizara Jan Blahoslav de los Evangelios de la Biblia de Kralice en la segunda mitad del siglo XVI. Del resurgimiento nacional checo hemos tomado una de las novelas más significativas del siglo XIX, La abuela de la autora Božena Němcová. Por último, como representante de la literatura checa contemporánea, la obra analizada ha sido Trenes rigurosamente vigilados de Bohumil Hrabal. A estos cuatro textos hay que sumar un análisis parcial de un texto que no está escrito en checo, sino en antiguo eslavo: el Codex Marianus ${ }^{2}$.

\section{PRINCIPIOS TEÓRICOS Y BASE METODOLÓGICA DEL ESTUdIO}

La cuestión de la relación entre datividad y animación en antiguo eslavo y checo ya fue objeto de un breve estudio cuyas principales con-

\footnotetext{
${ }^{2}$ Las razones por las que hemos decidido incluir el análisis de dicho texto, a pesar de no estar escrito en checo, así como una introducción sobre sus características, se desarrollarán en el apartado 3 .
} 
clusiones fueron recogidas en un artículo (Gutiérrez Rubio 2004). Si bien tanto la metodología de este nuevo análisis como sus objetivos serán a grandes rasgos los que ya utilizamos en dicho trabajo, hemos ampliado significativamente el número de textos a analizar ${ }^{3}$ y hemos perfeccionado la metodología del análisis, de modo que las conclusiones tanto diacrónicas como sincrónicas se han multiplicado de forma exponencial. Así, gracias a este análisis pretendemos mostrar cuál ha sido la relación entre la doble posibilidad desinencial en el dativo singular masculino $-u /-$ ovi y la categoría de animación a lo largo de todo el desarrollo de la lengua checa.

En cuanto a los principios teóricos y a la base metodológica que hemos aplicado a este estudio, resulta necesario destacar el trabajo de Igartua 2005, donde éste desarrolla en gran profundidad el origen, la difusión y la evolución de la categoría de animación en las lenguas eslavas. Aquí se pueden encontrar las claves necesarias para entender el fenómeno de la animación eslava y su reflejo diacrónico en el sistema casual de las distintas lenguas eslavas históricas, incluida la checa.

Una segunda obra de referencia que ha resultado básica para la concepción de nuestro análisis es el artículo de Huntley 1993, en el que se describe una jerarquía de animación similar a la que pretendemos emplear nosotros, si bien Huntley la diseña para el estudio del sincretismo genitivo-acusativo en antiguo eslavo y nosotros, por el contrario, para el estudio semántico-morfológico del dativo en antiguo eslavo y a lo largo de toda la historia de la lengua checa.

En su análisis, Huntley divide el léxico de los sustantivos de antiguo eslavo en doce categorías según su grado de animación, de modo que forman una jerarquía de animación. Su distribución es decreciente y va desde los sustantivos con un mayor grado de animación, los nombres propios de persona, hasta los del grado de animación más bajo, los sustantivos inanimados. A cada grado de la escala le corresponden dos columnas. La primera representa el número total de ocasiones en que se documenta ese nivel de animación concreto en los textos sin sincretismo genitivo-acusativo, mientras que la segunda columna representa la cifra con sincretismo. Estas cifras, que se hallan entre paréntesis, van acompañadas del tanto por ciento que representa cada una de estas dos columnas en el porcentaje total de cada grado de animación. Los resultados del estudio de Huntley pueden resumirse en la siguiente tabla:

\footnotetext{
lice.

${ }^{3}$ Entonces nos redujimos al estudio de dos únicos textos: Codex Marianus y Biblia de Kra-
} 


\begin{tabular}{|c|c|c|}
\hline & Nominativo-Acusativo & Genitivo-Acusativo \\
\hline 1. Nombre propio de persona & $0,4 \% \quad(3)$ & $99,6 \% \quad(790)$ \\
\hline 2. Nombre común de persona & $2,4 \% \quad(27)$ & $97,6 \%(1.109)$ \\
\hline 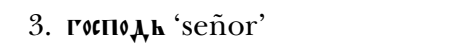 & $2,8 \%(5)$ & $97,2 \% \quad(173)$ \\
\hline 4. pak'h 'siervo' & $13,4 \% \quad(15)$ & $86,6 \% \quad(97)$ \\
\hline 5. '‘hIN'h 'hijo' (como adulto) & $20,8 \% \quad(30)$ & $79,2 \% \quad(114)$ \\
\hline 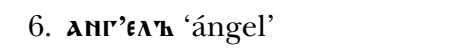 & $57,1 \% \quad(8)$ & $42,9 \% \quad(6)$ \\
\hline 7. Animales & $70,3 \% \quad(52)$ & $29,7 \% \quad(22)$ \\
\hline 8. '‘hımh 'hijo' (como niño) & $78,6 \% \quad(22)$ & $21,4 \% \quad(6)$ \\
\hline 9. $\mathbf{k} \mathbf{k} \mathbf{c h}$ 'demonio' & $87,5 \% \quad(35)$ & $12,5 \% \quad(5)$ \\
\hline 10. Niños & $90,5 \% \quad(19)$ & $9,5 \% \quad(2)$ \\
\hline 11. AorX'⿳⺈ 'espíritu' & $90,9 \% \quad(110)$ & $9,1 \%(11)$ \\
\hline 12. Nombre inanimado & $96,3 \%(2.557)$ & $3,7 \% \quad(97)$ \\
\hline
\end{tabular}

El estudio de Huntley nos muestra que, en efecto, existe una jerarquía de animación en antiguo eslavo y que de ésta depende la frecuencia con que aparece la desinencia de genitivo por la de acusativo. Asimismo nos señala que la categoría de animación no es un valor absoluto, sino que existe un grado de animación para cada sustantivo, y que mientras que el mayor grado de animación es para los nombres propios de persona, el de menor es para los sustantivos inanimados. Además, ni siquiera estos valores extremos presentan un $100 \%$ de grado de sincretismo nominativo-acusativo o genitivo-acusativo, respectivamente.

Para el análisis de los distintos textos que forman nuestro corpus hemos realizado una revisión del modelo de Huntley, de modo que sus principios teóricos sean aplicables a las necesidades de nuestra propia investigación:

1. Nombre propio de persona.

2. Profesión/ocupación.

3. Parentesco.

4. Gentilicio.

5. Ente no humano (incluye las palabras para Dios, ángel, demonio, etcétera).

6. Fauna.

7. Referente animado individual (incluye los sustantivos de referente animado que por falta de concreción no tengan cabida en las categorías precedentes, como la palabra persona). 
8. Referente animado colectivo (incluye los sustantivos que hagan referencia a colectivos animados como nación, gente, pueblo e incluso mundo).

9. Flora

10. Topónimo.

11. Nombre común inanimado.

\section{ESTUdiO SEMÁNTICO-MORFOLÓGICO EN ANTIGUO ESLAVO (CODEX MARIANUS)}

Si bien es cierto que el interés de nuestro estudio y análisis se centra en la lengua checa y en las distintas etapas de su desarrollo, creemos de gran interés remontarnos, en la medida de nuestras posibilidades, al testimonio literario más arcaico de una lengua eslava. Queremos dejar claro ya desde el principio - con el fin de evitar malentendidos- que los textos en antiguo eslavo no son antecesores directos de la lengua checa, como sí lo serían los textos, desgraciadamente inexistentes, del estadio denominado eslavo común. Así, el antiguo eslavo no refleja la realidad lingüística de los hablantes de checo de la época, sino la variante eslava meridional, eso sí, con distintos tipos de recensiones en función de la zona geográfica de influencia en la redacción y de la procedencia de los escribas.

A pesar de esto y puesto que, lamentablemente, no existen textos checos que se remonten hasta las fechas de creación de los textos en antiguo eslavo, creemos que el análisis del Codex Marianus resulta de gran interés para contrastar los datos históricos del checo con el testimonio literario más arcaico de una lengua eslava, muy cercana al estadio del eslavo común. Además, y de acuerdo con los especialistas, el Codex Marianus es el menos innovador de los textos de antiguo eslavo en lo relativo a la morfología y, por tanto, el más cercano a la situación reconstruida para el eslavo común, antecesor directo, éste sí, de la lengua checa.

El Codex Marianus data de finales del siglo X o principios del XI. Fue descubierto por el estudioso ruso Víktor Grigórovič en un viaje que realizó los años 1844 y 1845 al monte Athos y a las tierras eslavas de la Península Balcánica. Se trata de un tetraevangelio casi completo ${ }^{4}$ de características dialectales búlgaro-occidentales (macedonias) y con algunos rasgos serbios. Respecto a la morfología es muy arcaizante, aunque es menos conservador respecto a la ortografía que el otro gran manuscrito glagolítico, el Codex Zographensis.

\footnotetext{
${ }^{4}$ Faltan los folios 1-2, es decir, desde el inicio del Evangelio de Mateo hasta Mt 5.23. Además de otros dos fragmentos que van de Mt 6.16 a Mt 6.17 y de Jn 21.17 hasta el final del Evangelio.
} 
Para el estudio del Codex Marianus nos hemos servido no sólo de la edición clásica de Jagić 1883 que incluye el texto completo del tetraevangelio, sino además de la edición electrónica del texto, de libre acceso en la página web de la universidad de Helsinki ${ }^{5}$.

En lo que respecta a la situación formal del dativo en antiguo eslavo cabe decir que, al igual que ocurre en la mayoría de las lenguas eslavas históricas, presenta un alto grado de morfologización nominal, con la existencia de siete casos que se declinan según temas y no según el género: nominativo, genitivo, dativo, acusativo, vocativo, locativo e instrumental. De entre los temas del antiguo eslavo hay dos que resultan especialmente interesantes para el objeto de nuestro análisis: los temas masculinos temáticos y los temas en $-\breve{u}$.

Si comenzamos con la declinación no palatal de los sustantivos temáticos masculinos, se ha podido reconstruir que la desinencia de dativo singular etimológica es -or $(-u)$. Sin embargo, con frecuencia se documenta en los textos la terminación -окн (-ovi) procedente de los temas en $-\breve{u}$. Esta doble posibilidad formal en dativo singular responde al creciente proceso de fusión de ambos temas en un único paradigma, tendencia esta ya claramente apreciable en los primeros textos eslavos y que concluye con la fusión completa de ambos temas en todas las lenguas eslavas actuales. Por su parte, en la declinación palatal de los sustantivos temáticos masculinos, a las desinencias no palatales -оy, -окн $(-u /-o v i)$ les corresponden las palatales - $\mathbf{0},-\mathbf{\epsilon} \mathbf{K} \mathbf{H}(-j u /-e v i)$.

Si nos fijamos ahora en los temas en $-\breve{u}$, cabe afirmar que se trata de un paradigma no productivo que se ve envuelto en un proceso de fusión con los temas temáticos. A los temas en $-\breve{u}$ pertenece un limitado número de sustantivos masculinos, entre los que destacan, dada la elevada frecuencia con que se encuentran en los manuscritos de antiguo eslavo, los sustantivos ' 'hIn'h 'hijo' y A AMM'h 'casa'. Al igual que resulta frecuente que los sustantivos temáticos presenten una desinencia de dativo singular -окH, es usual encontrar sustantivos de tema $-\breve{u}$ con la terminación -oy distinta a la etimológicamente esperable -окН.

El nivel de desarrollo de la fusión entre los temas temáticos y los temas en $-\breve{u}$ se encuentra tan evolucionado en este periodo que las desinencias de los temas en $-\breve{u}$ dejaron de representar un paradigma independiente mucho antes de los primeros textos eslavos.

En lo concerniente a la expansión de la desinencia de dativo singular -оKH desde los temas en - $\breve{u}$ a los temáticos, es posible afirmar que se trata de un proceso complejo, pues no sucede de manera indiscriminada en todos los sustantivos masculinos, sino que juega un papel decisivo la semántica de cada sustantivo y, más concretamente, la categoría de animación. Todos los autores consideran que esta tendencia es más

${ }^{5}<$ http://www.slav.helsinki.fi/ccmh/MAR.TXT>. 
evidente entre los sustantivos animados que hacen referencia a personas y, muy especialmente, entre los nombre propios de persona.

Antes de desarrollar las gráficas con los datos extraídos del análisis del Codex Marianus es necesario aclarar que se han tenido en cuenta exclusivamente los sustantivos masculinos temáticos y de tema en $-\breve{u}$ que presenten en el manuscrito una terminación de dativo singular -окН/-єКН (-ovi/-evi) о -or/-н $(-u /-j u)$.

En el Codex Marianus se documentan 386 entradas, de las cuales $284[74 \%$ ] se corresponden a la desinencia $(-u)$ y 102 [26\%] a la desinencia $(-o v i)$.

TABla 1a: Desinencias de dativo (Codex Marianus).

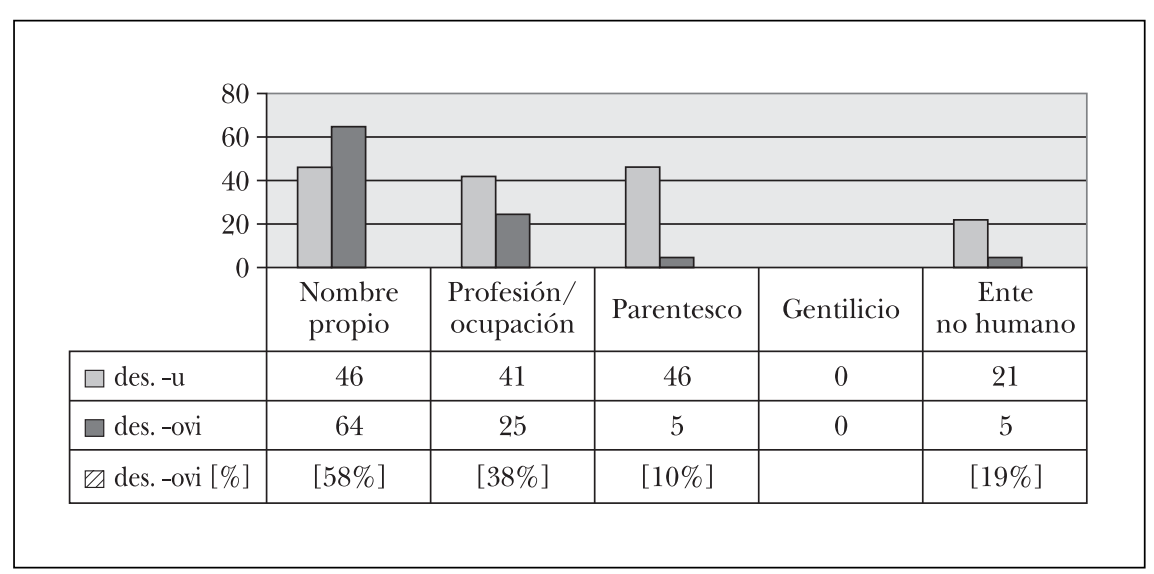

TABLa 1b: Desinencias de dativo (Codex Marianus).

\begin{tabular}{|c|c|c|c|c|c|c|}
\hline \multicolumn{7}{|c|}{80} \\
\hline 60 & & & & & & \\
\hline \multicolumn{7}{|l|}{40} \\
\hline 20 & 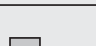 & & & & 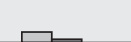 & \\
\hline 0 & Fauna & $\begin{array}{l}\text { Ref. anim. } \\
\text { individual }\end{array}$ & $\begin{array}{l}\text { Ref. anim. } \\
\text { colectivo }\end{array}$ & Flora & Topónimo & $\begin{array}{l}\text { Nombre } \\
\text { común }\end{array}$ \\
\hline$\square$ des. -u & 4 & 27 & 29 & 0 & 4 & 66 \\
\hline$\square$ des. -ovi & 0 & 1 & 0 & 0 & 1 & 1 \\
\hline$\square$ des. -ovi $[\%]$ & {$[0 \%]$} & {$[4 \%]$} & {$[0 \%]$} & & {$[20 \%]$} & {$[1 \%]$} \\
\hline
\end{tabular}


TABLA 2: Resumen desinencias de dativo (Codex Marianus).

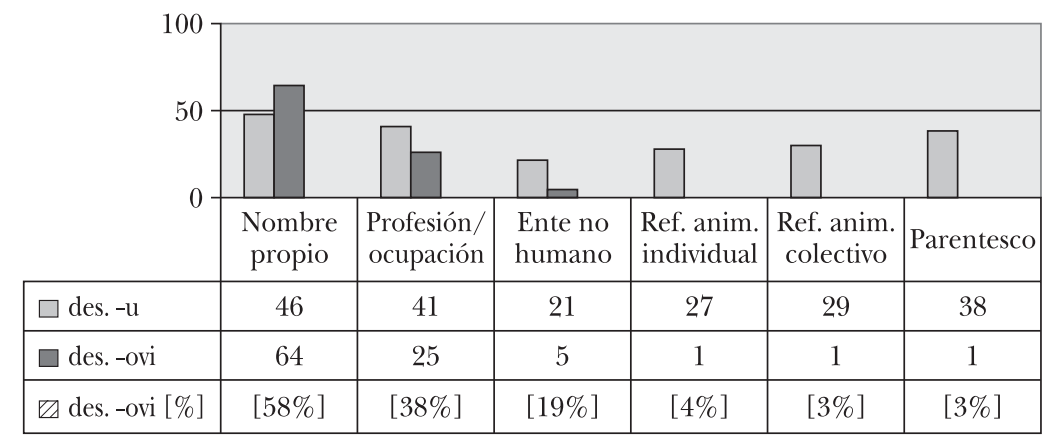

TABla 3: Desinencias de dativo según los temas (Codex Marianus).

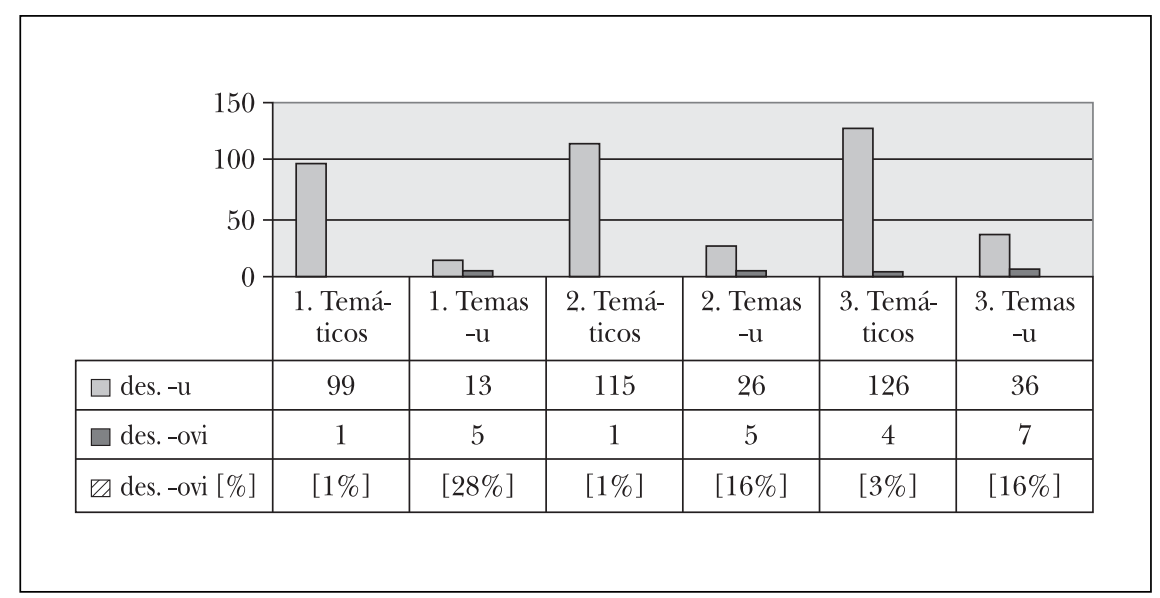

Comenzaremos el análisis de los textos prestando atención a la tabla número 3 , que nos muestra los porcentajes de las desinencias $-u$ y -ovi para los temas temáticos y los temas en $-\breve{u}$, y que nos ha de aclarar en qué medida continúa vigente la diferencia formal en dativo entre los sustantivos de los temas temáticos y los de los temas en - $\breve{u}$. Dado que no existe un criterio absolutamente claro sobre las palabras que pertenecen etimológicamente a los temas en $-\breve{u}$ y las que no, hemos seguido la clasificación de Janda 1996, p. 327, que divide las palabras con 
origen en los temas en - $\breve{u}$ en cuatro categorías, desde las palabras que con certeza pertenecen a los temas en $-\breve{u}$ hasta las que presentan un origen cuestionable ${ }^{6}$.

De entre nuestro listado de palabras se documentan ocho pertenecientes a tres de las clasificaciones expuestas por Janda. En primer lugar, entre las que con certeza son temas en $-\check{u}$, se documentan dos: chIMh 'hijo' y A.MMTh 'casa'. Al comparar las frecuencias para estas dos palabras con el resto de las que pertenecen exclusivamente a sus respectivas clases semánticas (Parentesco y Nombre común) los resultados son los que aparecen en las dos primeras columnas de la tabla 3 (28\% frente a $1 \%$ ).

En la columna «2-Temas en $u »$ hemos añadido los datos referidos a los tres sustantivos que según la clasificación de Janda son posibles temas en $-\breve{u}$ y cuya forma de dativo se documenta en el Codex Marianus:

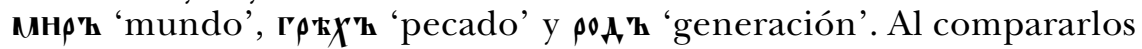
con los resultados temáticos de las categorías a las que estas palabras pertenecen, encontramos que las diferencias disminuyen, pero aun así son considerables ( $1 \%$ frente a $16 \%$ ). Por último, hemos analizado en las dos últimas columnas los resultados incluyendo aquellos sustantivos que Janda duda puedan pertenecer a los temas en - $\breve{u}$ : MXжh 'hombre',

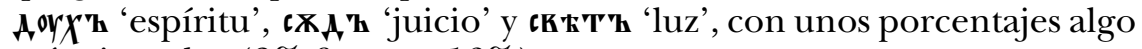
más ajustados (3\% frente a $16 \%)$.

La conclusión que debemos extraer de estos datos (consideremos como sustantivos de tema en - $\breve{u}$ un grupo más o menos amplio, y sin entrar a discutir los parámetros empleados por los distintos autores para conformar sus listas de sustantivos de tema en $-\breve{u}$ ) es que existe una clara tendencia a que los sustantivos de tema en $-\breve{u}$ presenten con mucha mayor frecuencia la desinencia-ovi, lo que se ve confirmado por el hecho de que el único nombre común que presenta la desinencia -ovi sea, precisamente, AoMh 'casa', uno de los pocos que sin lugar a dudas procede de los temas en $-\breve{u}$.

En lo tocante a la validez de la jerarquía de animación respecto a la presencia o ausencia de la desinencia -ovi, semejante a la demostrada ya para el sincretismo genitivo-acusativo, las tablas $1 \mathrm{a}$ y $1 \mathrm{~b}$ nos muestran que dicha hipótesis queda confirmada con claridad entre los dos primeros escalones de la pirámide jerárquica: Nombre propio de persona (58\%) y Profesión/ocupación (38\%). A partir de aquí la configu-

\footnotetext{
${ }^{6}$ De entre los sustantivos nombrados en distintas obras como pertenecientes a los temas en $-\breve{u}$, hay seis que aparecen en todas las listas y que Janda, consecuentemente, califica como

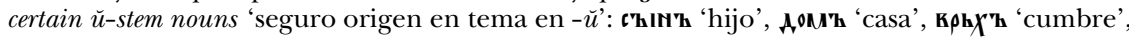
ME $\mathbf{A} \mathbf{h}$ 'miel', K0 $\mathbf{\Lambda} \mathbf{h}$ 'buey' y $\mathbf{\Pi 0 \boldsymbol { \Lambda } \mathbf { h }}$ 'mitad'. Otros sustantivos son calificados según su aparición

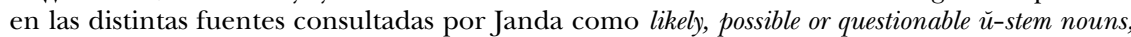
'probable, posible o cuestionable origen en tema en - $\breve{u}$ '. A esta lista hemos sumado un sustantivo incluido por Gardiner 1984, p. 38, en su propio listado y que no aparece en ninguno de los inventarios consultados por Janda: reponsh 'trueno'.
} 
ración de la escala de animación no es proporcional a los dos primeros escalones, e incluso puede resultar algo confusa, en parte por la presencia de sustantivos con origen en los temas en $-\breve{u}$ que pueden condicionar los resultados y, muy concretamente y como acabamos de ver, por la existencia de una desinencia -ovi entre los nombres comunes y que supone el $1 \%$.

Otro resultado muy llamativo es el $20 \%$ en la frecuencia de la desinencia de dativo -ovi documentado entre los topónimos. Sin embargo, este dato puede resultar engañoso, pues se trata de un único sustantivo, 'Israel', con desinencia -evi (нДАрандєкн), у que podría ser perfectamente considerado como referente animado colectivo, pues el evangelista Juan no hace referencia al país como realidad geográfica, sino al «pueblo de Israel».

En la tabla 2 de la sección precedente mostramos la jerarquía de animación del Codex Marianus con la exclusión de los sustantivos que con seguridad tienen su origen en los temas en $-\breve{u}$ ('chIM'h 'hijo' y A AMMh 'casa'), así como de todas las categorías en que no hemos documentado entradas con la desinencia -ovi (Gentilicio, Fauna, Flora y Nombre común). Además, hemos incluido el citado sustantivo НZ АранлєкН entre los Referentes animados colectivos. Una vez reordenados los datos según sus porcentajes, la jerarquía de animación para las desinencias de dativo -ovi, -evi en el Codex Marianus parece suficientemente demostrada.

$\mathrm{Al}$ igual que la de las desinencias genitivo-acusativo en antiguo eslavo, la pirámide de animación de las desinencias de dativo no es una escala absoluta. Sin embargo, muestra una tendencia clara a que a mayor grado de animación de los sustantivos, mayor sea la frecuencia con que se documenten con la desinencia -ovi.

\section{ESTUdio SEMÁNTICO-MORFOLÓGICO EN ANTIGUO CHECO (CRÓNICA DE DALIMIL)}

Como ya hiciéramos en el apartado 3 para un texto en antiguo eslavo, vamos a realizar un análisis pormenorizado de todas las formas de dativo singular masculino de la Crónica de Dalimil. Trataremos así de comprobar la hipotética relación entre las categorías de datividad y animación en checo antiguo.

Aunque el antiguo eslavo no forme parte de la evolución de la lengua checa, es posible establecer -dada su cercanía a lo que debió de ser el protoeslavo y, en alguna medida, el protocheco- una cierta línea continua entre el sistema declinacional de los sustantivos en antiguo eslavo y en antiguo checo. El proceso de redistribución del sistema declinacional que ya era observable en antiguo eslavo se encuentra en un estado 
de mayor evolución. El sistema declinacional combinado según temas y géneros se dirige hacia un sistema único según géneros. Parece que los temas en $-\breve{u}$ se fusionaron con los temas temáticos en antiguo checo en un periodo bastante antiguo, hasta acabar formando un único paradigma conjunto de género masculino. Vážný 1964, p. 70, afirma que ni siquiera en el checo de c. 1300 se puede hablar de estos temas como un tipo independiente respecto a los temas temáticos y en - $i$. Sin embargo, Gebauer 1960 advierte que la fusión con estos temas durante el estadio más arcaico del checo -es decir, hasta mediado el siglo XIV- no era tan absoluta como lo sería con posterioridad.

Gebauer 1960, pp. 326-334, aporta una lista de los sustantivos de tema en - $\breve{u}$ que se han conservado en checo, lo que nos resultará de gran interés durante el análisis de la Crónica de Dalimil para comprobar si, como él argumenta, las desinencias de estos sustantivos conservan rasgos de su declinación diferenciada y, en el caso que nos ocupa en particular, si la frecuencia de la desinencia -ovi en el dativo es mayor que entre los sustantivos temáticos. Los más significativos son: bor 'pinar', čin 'orden', 'fila' (más tarde 'hecho'), dar 'don', dol 'parte baja', dom 'casa', $d u b$ 'roble', jëd 'veneno', jil 'barro', 'arcilla', led 'hielo', med 'miel', mir 'paz, mundo', pol 'medio', sad 'jardín', sled 'rastro', stan 'campamento', súd 'juicio', syn 'hijo', vol 'buey' y vrch 'parte superior'.

La llamada Crónica de Dalimil es un texto de excepcional valor literario e histórico y la muestra más representativa de la primera literatura de creación propia en lengua checa. Su redacción se remonta hasta principios del siglo XIV, en torno a 1310. Es una obra en verso de una extensión considerable llevada a cabo por el movimiento cultural de la nobleza checa opuesta a las influencias germánicas, tanto de carácter político como cultural. En el estudio que hemos realizado de la Crónica de Dalimil no nos hemos reducido a analizar las formas de un único manuscrito, sino que hemos realizado un estudio de las desinencias de dativo singular de todos los manuscritos y fragmentos conservados ${ }^{7}$. Esto nos ha proporcionado un número muy superior de entradas respecto al resto de los textos que conforman el análisis de esta investigación.

Sin embargo, con la intención de facilitar el estudio de un número tan elevado de datos no hemos analizado uno por uno cada manuscrito en busca de las desinencias y pronombres de dativo singular, sino que hemos elegido entre todos los manuscritos conservados el que hemos

\footnotetext{
${ }^{7}$ Las quince fuentes conservadas de la Crónica de Dalimil son: Fragmento de Hanuš - H, Fragmentos de Hradec - Hr, Fragmento de Olomouc - O, Fragmentos de Munich - M, Fragmentos clementinos y Fragmentos de los cruzados - K, Fragmento de Strahov - S, Manuscrito de Cambridge - C, Manuscrito franciscano - F, Manuscrito de Viena - V, Manuscrito de Lobkovice - L, Manuscrito de Pelcel-P, Manuscrito de Cerroni-Cr, Manuscrito de Fürstenberg-Fs, Manuscrito de Zeberer-Z, edición de Ješin - Jš.
} 
considerado más adecuado para nuestra investigación -en este caso el Manuscrito de Viena (V) por ser el más similar a la fuente original-y confrontado la información de éste con todos los demás textos.

Por otra parte, resulta necesario subrayar que para el análisis seguiremos en todo momento la edición de los distintos manuscritos y fragmentos recogida en los dos tomos de Daňhelka, Hádek, Havránek y Kvítková 1988 a y b. La numeración de los capítulos y versos será siempre la de $\mathrm{V}$, tal y como se propone en la edición que nos sirve de fuente principal.

Comenzaremos el análisis de los textos prestando atención a las tablas número 4a y 4b, que reflejan los resultados obtenidos en el Manuscrito de Viena. Si observamos estas gráficas, de inmediato comprobaremos que, efectivamente, existe una jerarquía de animación entre los dos pri-

TABla 4a: Desinencias de dativo (Crónica de Dalimil-Manuscrito de Viena).

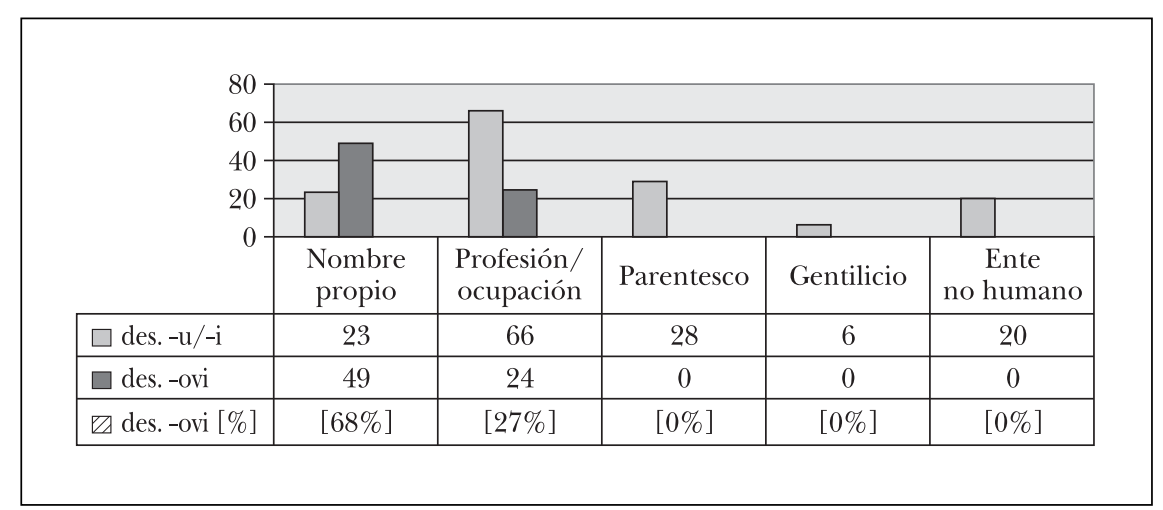

TABla 4b: Desinencias de dativo (Crónica de Dalimil-Manuscrito de Viena).

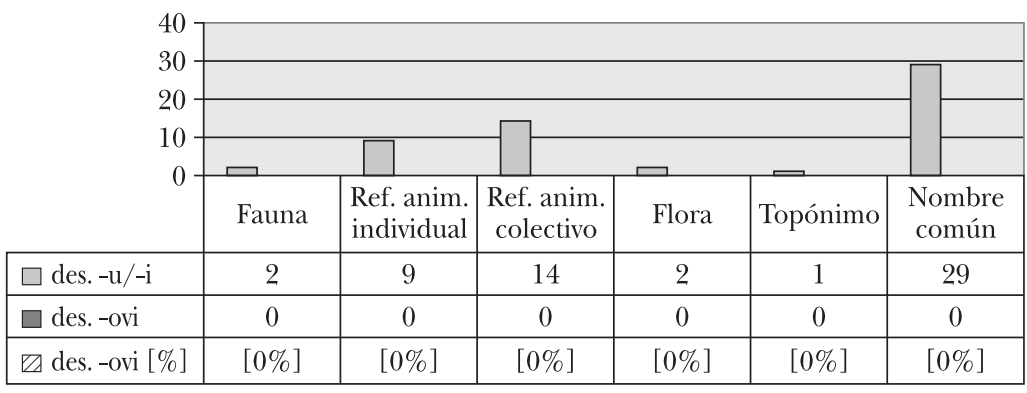


TABLA 4c: Desinencias de dativo (Crónica de Dalimil-Todos los manuscritos).

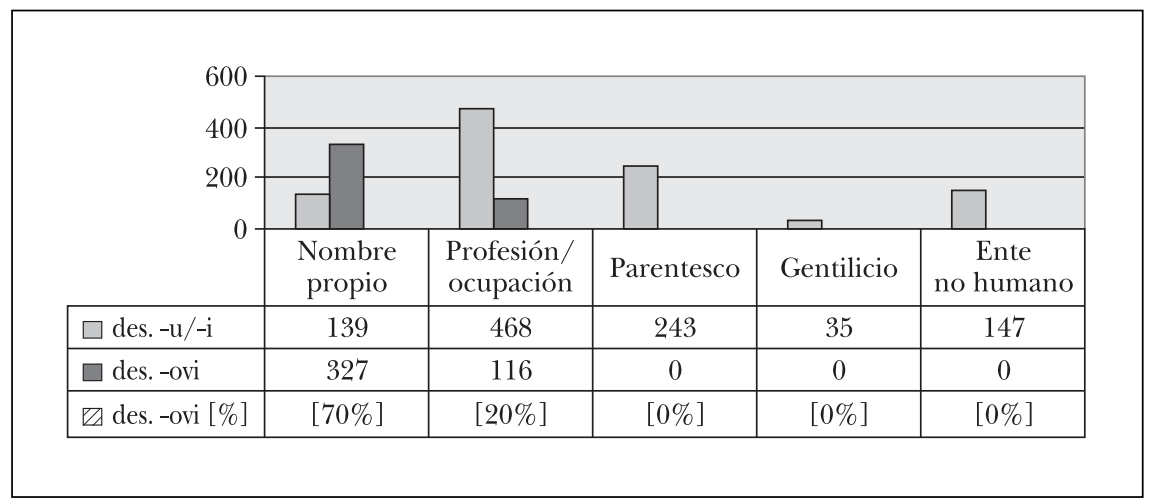

TABLA 4d: Desinencias de dativo (Crónica de Dalimil-Todos los manuscritos).

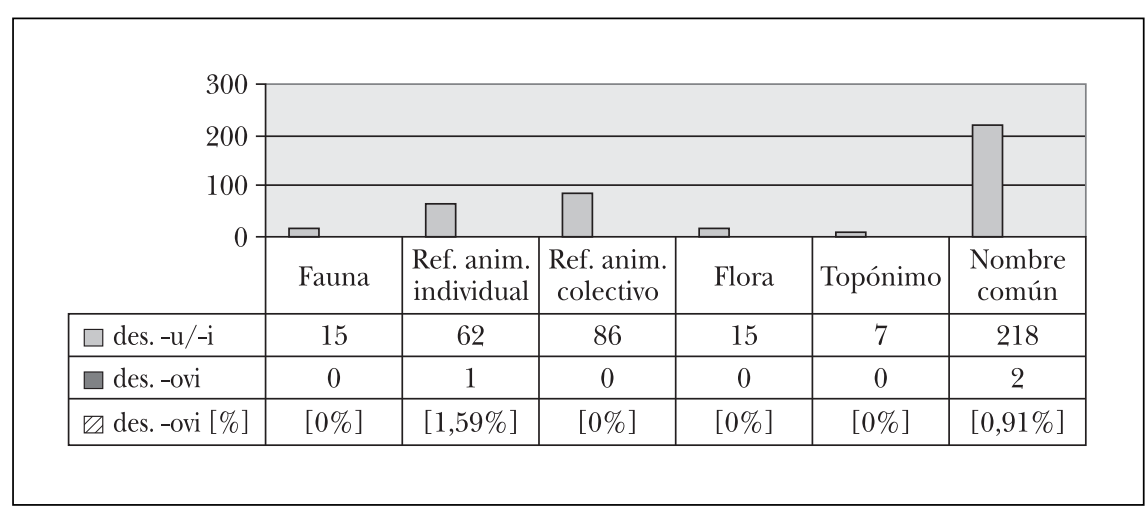

TABla 4e: Desinencias de dativo (Crónica de Dalimil-Análisis individualizado).

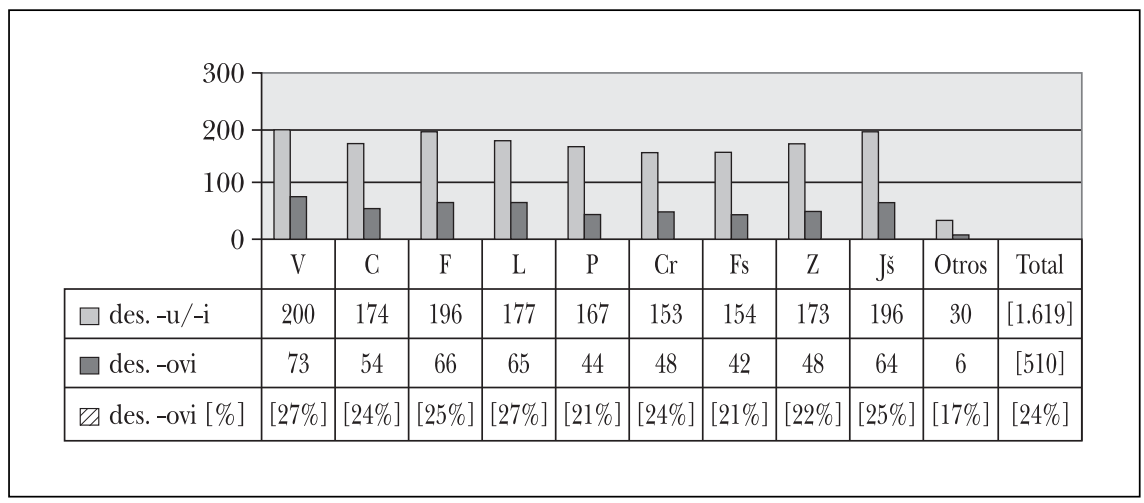


TABLA 4f: Nombre propio de persona (Crónica de Dalimil-Análisis individualizado).

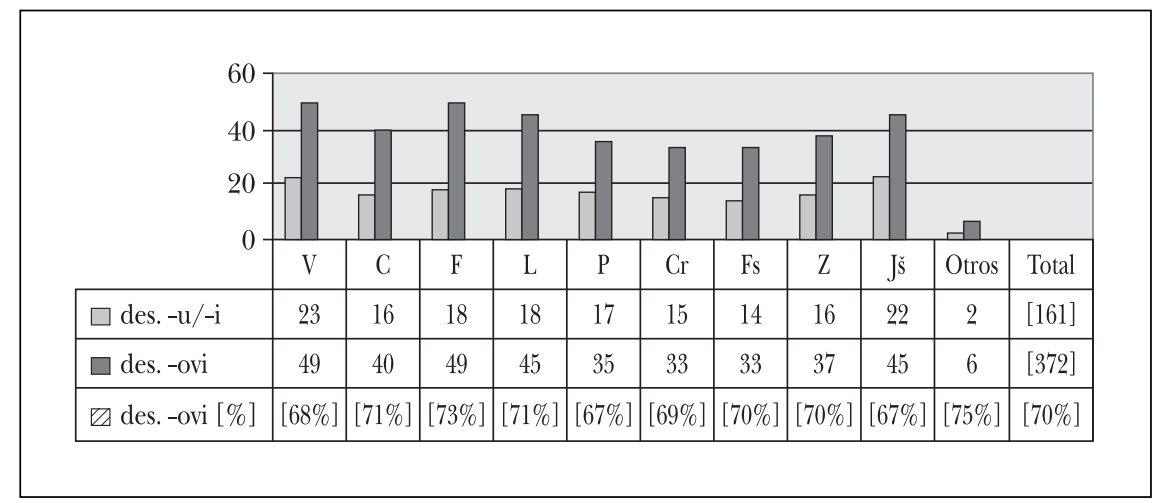

TABla 4g: Profesión/ocupación (Crónica de Dalimil-Análisis individualizado).

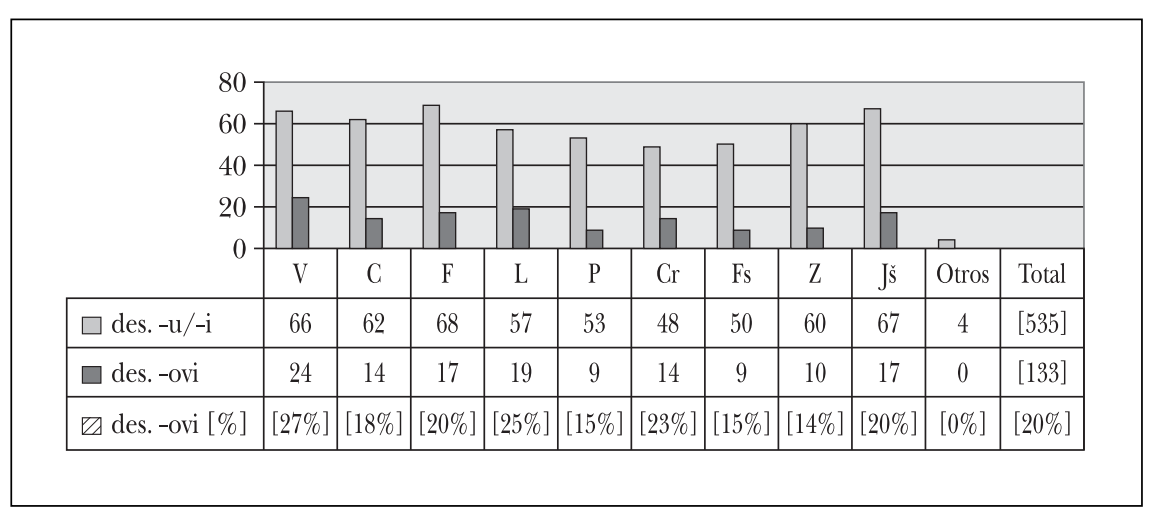

meros escalones, «Nombre propio de persona» (68\%) y «Profesión/ocupación» (27\%), mientras que para el resto de las clases no se documenta ni un único sustantivo con desinencia -ovi.

Si comparamos estos guarismos, en primer lugar, con los que obtuvimos para el Codex Marianus -con la exclusión de los sustantivos que

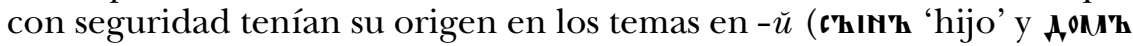
'casa')- observamos unos porcentajes muy similares: $58 \%$ y $38 \%$ respectivamente. Se distingue, sin embargo, una tendencia ya evidente en checo antiguo a marcar aún más con la desinencia -ovi los sustantivos que se sitúan en los más alto de la escala de animación al mismo tiempo que, por el contrario, se marca con menor frecuencia los del segundo escalón. Esta tendencia es aún más intensa al alejarnos del manuscrito original, es decir, al observar la suma de los resultados de todos los 
manuscritos conservados 8 , ya que estos porcentajes -y como puede observarse en las gráficas 4c y 4d-, son del $70 \%$ y $20 \%$ respectivamente.

Además, ninguno de los textos analizados en particular rompe esta tendencia, sino que todos ellos presentan unos porcentajes que se sitúan ampliamente por encima del valor de los «Nombres propios de persona» del Codex Marianus (con unos porcentajes que van entre el $67 \%$ y el $75 \%$ ) y por debajo del de «Profesión/ocupación», (con unas cifras entre el $14 \%$ y el $27 \%$ ), como puede observarse en las tablas $4 \mathrm{c}$ y $4 \mathrm{~d}$.

Estos porcentajes son aún más significativos si reducimos el análisis de los datos a los sustantivos de los temas temáticos acabados en consonante y excluimos, por tanto, los sustantivos masculinos que resultan problemáticos a la hora de encajar en este paradigma y, muy especialmente, los sustantivos de los temas en - $a$ masculinos. Tras esta reorganización de los datos obtenemos una frecuencia de la desinencia -ovi del $83 \%(327 / 65)$ para los «Nombres propios de persona» (frente al $70 \%$ documentado anteriormente) y un $21 \%$ (116/422) para la clase «Profesión/ocupación» (frente al 20\%).

Esta evidente jerarquía de animación observable no solo en el $M a^{-}$ nuscrito de Viena, sino en todos los demás manuscritos, está distorsionada por un mínimo porcentaje de sustantivos que sí presentan las desinencia -ovi, pero que no pertenecen a los dos primeros escalones de la escala de animación. En concreto son tres sustantivos, lo que en relación con las 1.819 entradas que hemos analizado significan apenas el $0,16 \%$ del total de manuscritos y fragmentos. Incluso reduciendo el cálculo a los nueve campos semánticos que no presentan habitualmente desinencias en -ovi, es decir, excluyendo los campos «Nombre propio de persona» $\mathrm{y}$ «Profesión/ocupación», encontramos un total de 821 entradas, para las que los tres sustantivos con -ovi representan tan solo el $0,36 \%$ del total.

Otro elemento destacable del análisis es la escasa variación entre las distintas fuentes. El gráfico número 3 muestra que -excluyendo la columna «Otros», poco representativa por ser un análisis de apenas 36 sustantivos- todas las fuentes se sitúan en un espectro de frecuencia de la desinencia -ovi de entre el $21 \%$ y el $27 \%$, lo que consideramos una diferencia relativamente escasa.

Además, tras el análisis de los datos podemos concluir que -como afirma Gebauer 1960- existe una tendencia demostrada a que los nombres de santos, posiblemente por analogía semántica respecto al sustan-

\footnotetext{
8 A esta suma de los resultados parciales de todos los manuscritos le hemos añadido los guarismos obtenidos para los distintos fragmentos, cuya suma hemos englobado bajo el encabezado «Otros». Los datos obtenidos para la primera edición impresa de la crónica (Jš) han sido excluidos, tanto por tratarse de una edición muy tardía (1620) como porque el texto final responde al conocimiento y a la concepción que su editor Ješín de Bezděz tenía del checo antiguo, en muchos casos erróneos.
} 
tivo Bůh 'Dios' que apenas documenta la forma Bohovi, presenten la desinencia no marcada $-u /-i$.

Por otra parte, Gebauer 1960 nos advierte en su gramática histórica de que el uso de -ovi es particularmente frecuente en sustantivos que carecen de complementos, mientras que en sustantivos acompañados de complementos pueden aparecer por igual tanto la desinencia $-u$ como la desinencia -ovi. Sin embargo, de los siete nombres propios de persona que presentan la desinencia $-u /-i$ hay cinco que lo hacen en ausencia de complemento -Alexander $(\times 4)$, Bořivoj $(\times 1)$, Lokr $(\times 1)$, Rudoltovic $(\times 3)$ y Strachkvas $(\times 1)$ - lo que supone el $71 \%$ del total de entradas con desinencia $-u /-i$. El resto, kněz Přěmysl 'príncipe Přěmysl' (×3) y král Svatopluk 'rey Svatopluk' $(\times 1)$, significan el restante $29 \%$ de entradas con desinencia $-u /-i$. Por lo visto hasta aquí, resulta muy difícil creer que lo que afirma Gebauer sobre las frecuencias sea aplicable a los sustantivos de la clase «Nombre propio» de persona en nuestro texto.

Entre el resto de sustantivos animados, la afirmación de Gebauer sí parece cumplirse, ya que -aunque se documenten ejemplos como Strachkvasovi mnichovi 'al monje Strachkvas' (P) - la mayoría de los sustantivos que acompañan a uno de los pertenecientes a la clase «Nombre propio» presentan la desinencia $-u /-i$. Un buen ejemplo de esto es la palabra král 'rey'. Cuando aparece sola presenta la desinencia -ovi con una frecuencia del $74 \%$ (57/20), lo que está muy por encima del $20 \%$ aproximado de frecuencia de esta desinencia en los sustantivos de su clase («Profesión/ocupación»). Sin embargo, al documentarse junto a un complemento, la frecuencia se reduce al $50 \%$ (12/12), si bien hay que tener en cuenta que, si ese complemento es un adjetivo, la presencia de -ovi muestra una frecuencia del $75 \%$ (12/4), es decir, se mantiene en las mismas cifras que sin presencia de un complemento. Sin embargo, cuando antecede a otro sustantivo, encontramos exclusivamente la forma králi, es decir, el $0 \%(0 / 8)$ de frecuencia de la desinencia -ovi. La tendencia apuntada por Gebauer queda así demostrada para los sustantivos animados distintos de los nombres de persona, si bien resulta imprescindible decir que ésta depende de la propia capacidad de algunas palabras para presentar la desinencia-ovi, como demuestra el hecho de que el sustantivo kněz 'príncipe' presente un $0 \%(0 / 286)$ de frecuencia en la desinencia -ovi, de forma absolutamente independiente a la ausencia o la presencia de complemento o de la fuente donde se documente.

En cuanto a la posibilidad expuesta por Gebauer 1960 de que los sustantivos que etimológicamente pertenecieran a los temas en - $\breve{u}$ puedan presentar una mayor frecuencia en las desinencias que proceden originariamente de este tema, queda demostrado que, al menos en lo relativo a la desinencia -ovi de dativo singular, esta posibilidad no se cumple en checo antiguo. El único sustantivo que se documenta en dativo singular en la Crónica de Dalimil de los listados por Gebauer es syn 
'hijo'. Se trata del candidato perfecto para demostrar o no esta posibilidad, tanto por su condición de sustantivo animado, como por ser junto a dom 'casa' el único sustantivo al que todos los autores sin excepción sitúan entre los que tienen su origen etimológico en los temas en - $\breve{u}$. Sin embargo, las treinta entradas pertenecientes a diez ediciones distintas de la crónica presentan como única forma de dativo singular synu.

Ni siquiera ampliando la lista de Gebauer con los sustantivos que aporta Janda y que son, a fin de cuentas, todos aquellos que se sospecha que pudieran haber pertenecido etimológicamente a los temas en - $\breve{u}$, encontramos, en un total de 61 sustantivos en dativo singular, ni siquiera una única desinencia -ovi.

\section{ESTUdiO SEMÁNTICO-MORFOLÓGICO EN CHECO HUMANISTA (Biblia de Kralice)}

Como ya hiciéramos en el apartado anterior para la Crónica de Dalimil, en éste apartado vamos a realizar un análisis pormenorizado de todas y cada una de las formas de dativo singular masculino. En este caso, hemos escogido para ilustrar el checo humanista (aprox. 1500-1650) los Evangelios de la Biblia de Kralice.

Hemos escogido este texto porque supuso un momento de inflexión decisivo para el ulterior desarrollo de la lengua checa. Su aportación a la norma de la lengua checa es inmensa ya desde el mismo momento en que vio la luz, si bien es necesario reconocer que no se trata de una nueva lengua o ni siquiera del desarrollo del dialecto de su autor, Jan Blahoslav, o de aquellos que continuaron su obra. La lengua de la Biblia de Kralice se asienta en la tradición -y, muy especialmente, en la de Jan Hus- en una fase ulterior de su desarrollo y perfeccionamiento. Dada su claridad y corrección se convirtió en el modelo clásico de la lengua checa a imitar por los escritores más prestigiosos, pues se decía que no existía mejor lengua checa que ésta.

El origen de la traducción se remonta a mediados del siglo XV y se enmarca dentro del movimiento reformista centroeuropeo de la época. En cuanto a Jan Blahoslav (1523-1571), cabe decir que entre su producción sobresalen especialmente la traducción de las Sagradas Escrituras y su gramática de la lengua checa, que finalizó poco antes de morir y en la que plasma algunos de los conocimientos prácticos adquiridos durante la traducción del Nuevo Testamento.

En cuanto a la fuente concreta para el análisis, nos hemos servido -por una cuestión evidente de practicidad- de una edición electrónica de acceso libre ${ }^{9}$ y que, por supuesto, hemos confrontado concienzuda-

\footnotetext{
${ }^{9}<$ http://www.etf.cuni.cz/ rovnanim/bible/k/Mt1.php>.
} 
mente con el texto impreso correspondiente, en este caso, con la edición de varios fragmentos realizada por Hrozný 1913.

El análisis de la Biblia de Kralice nos aporta un total de 378 sustantivos en dativo, de los cuales 262 presentan la desinencia $-u /-i$ [69\%] por 116 que presentan la desinencia -ovi [31\%].

Un primer análisis de los datos nos muestra una evidente jerarquización de la categoría de animación. A la cabeza de esta jerarquía se encuentran los «Nombres propios de persona». Las categorías «Profesión/ocupación»y «Parentesco», con una frecuencia de desinencias -ovi sustancialmente inferior (del $6 \%$ y $2 \%$ respectivamente), ocuparían el segundo y el tercer escalón.

TABLa 5a: Desinencias de dativo (Biblia de Kralice).

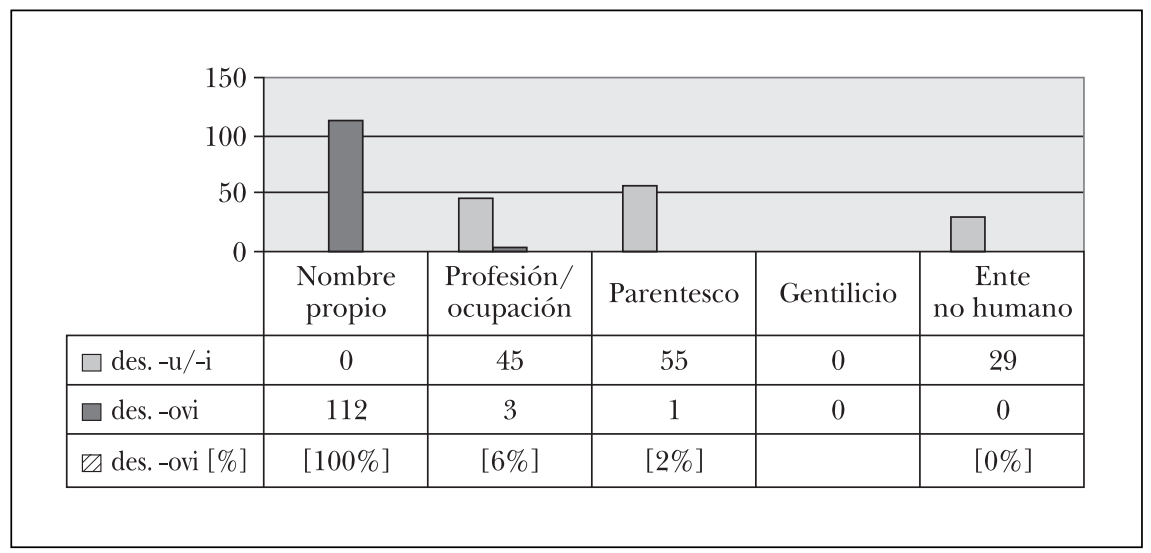

TABla 5b: Desinencias de dativo (Biblia de Kralice).

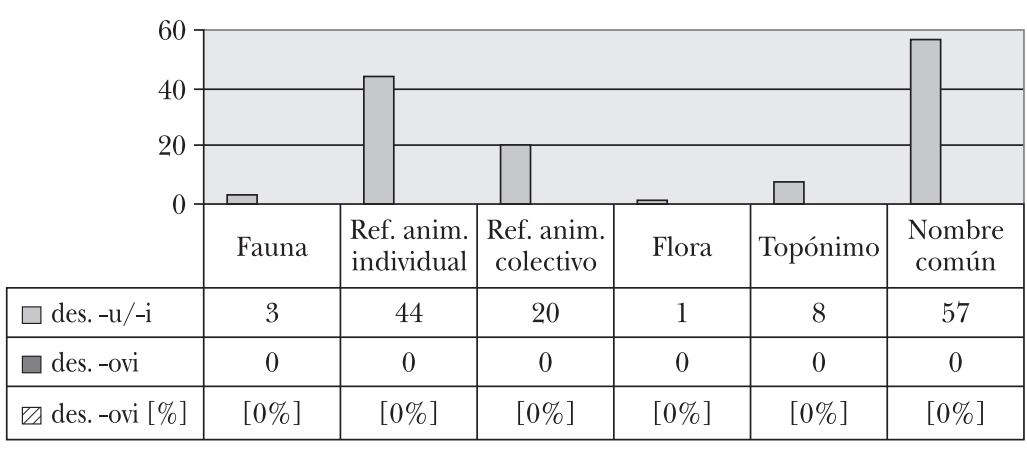


Sin embargo, un análisis más profundo de los datos nos ofrece una segunda interpretación. Los cuatro únicos ejemplos de sustantivos animados que no pertenecen a la categoría "Nombre propio de persona» y presentan una desinencia -ovi son setníkovi 'al centurión', učedlnikovi 'al discípulo' $(\times 2)$ y ženichovi 'al marido'. Todos ellos son sustantivos que forman el vocativo en $-u$, lo que, de acuerdo con las normas expuestas por Jan Blahoslav en su gramática ${ }^{10}$, podría explicar la desinencia -ovi como un intento por diferenciar las formas de vocativo y dativo singular.

Así, no se trataría de una pirámide jerárquica como la atestiguada en antiguo eslavo y en checo antiguo, sino de una norma clara, según la cual todos los nombres propios de persona masculinos presentarían la desinencia -ovi y todos los demás sustantivos masculinos - $u$. Además, resulta plausible afirmar que existiría un cierto número de sustantivos animados que por sus propias características -y muy especialmente por la consonante en que termine la palabra- podrían presentar una desinencia de dativo singular -ovi. Es el caso de aquellos sustantivos animados que acaban en consonantes velares $k, c h, h, g$ y que para evitar la alternancia consonántica en la raíz, dada la palatización que suponía la combinación de estas consonantes velares con la desinencia de vocativo de los temas temáticos $-e$, forman el vocativo con la desinencia de vocativo $-u$, propia de los temas en $-\breve{u}$ (vrahu 'al asesino' $)^{11}$. En cualquier caso, no se trata de una norma clara, pues la mayoría de las formas de dativo singular de sustantivos que forman el vocativo en $-u$ no se documenta con la desinencia-ovi.

\section{ESTUDIO SEMÁNTICO-MORFOLÓGICO EN EL CHECO DEL RESURGIMIENTO NACIONAL (LA ABUELA DE BOŽENA NĚMCOVÁ)}

Casi todos los autores coinciden en considerar que el último estadio en la historia de la lengua checa comienza en el último tercio del siglo XVIII, de la mano del movimiento social, político y cultural denominado resurgimiento nacional. A la lengua checa de este periodo se la denomina nová čeština 'checo nuevo' y se caracteriza por el proceso de

${ }^{10}$ En su Gramática, Blahoslav afirma respecto a las desinencias de dativo singular (cf. Hradil y Jireček 1857, p. 71): Variat quandoque dativus casus, Říkáme: Dej tomu postu list, postowi; prwní jest usitatum, druhé jest dětinské a ničemné, prorsus puerile vel muliebre. Ale zase lépe dís: dej dédkowi, a ne: dědku; nebo dědku jest vocativus casus. A protož vide, quid approbet usus. «En ocasiones el dativo tiene variantes. Decimos: Dej tomu postu list (da a este correo la carta), postowi; el primero [postu] es comúnmente usado, el segundo [postowi] es pueril y bellaco, francamente infantil o afeminado. Mas por otra parte mejor di: dej dědkowi (da al anciano), y no: dědku, porque dédku es caso vocativo. Y por eso, ten en cuenta lo que aprueba el uso».

11 Esta norma se generaliza en checo a excepción de dos sustantivos člověk 'persona' y bůh 'dios' que forman su vocativo con $-e$ y, por tanto, forman el dativo singular exclusivamente con $-u$. 
regulación y normalización que la ha llevado desde un momento inicial de relativa fluctuación o vacilación hasta la aceptación general de un modelo gramatical estable de la lengua literaria que, sin embargo, no se ve plenamente reflejado en el nivel oral y popular de la lengua checa.

No resulta sencillo describir con precisión el grado de normalización del uso de las desinencias de dativo singular $-u$ y -ovi a lo largo del siglo XIX. De ahí que uno de los objetivos de este artículo sea precisamente conocer ese grado de normalización a través del análisis de la novela más representativa de Božena Němcová (1820-1862) y posiblemente de todo este periodo de la lengua checa.

Para el análisis nos hemos servido de la reimpresión de una edición de 1942 (Němcová 2001). En total, La abuela recoge 313 entradas de dativo masculino singular, de las que 242 se forman con la desinencia $-u /-i[77 \%]$ y 71 con - ovi $[23 \%]$.

TABLa 6a: Desinencias de dativo (La abuela).

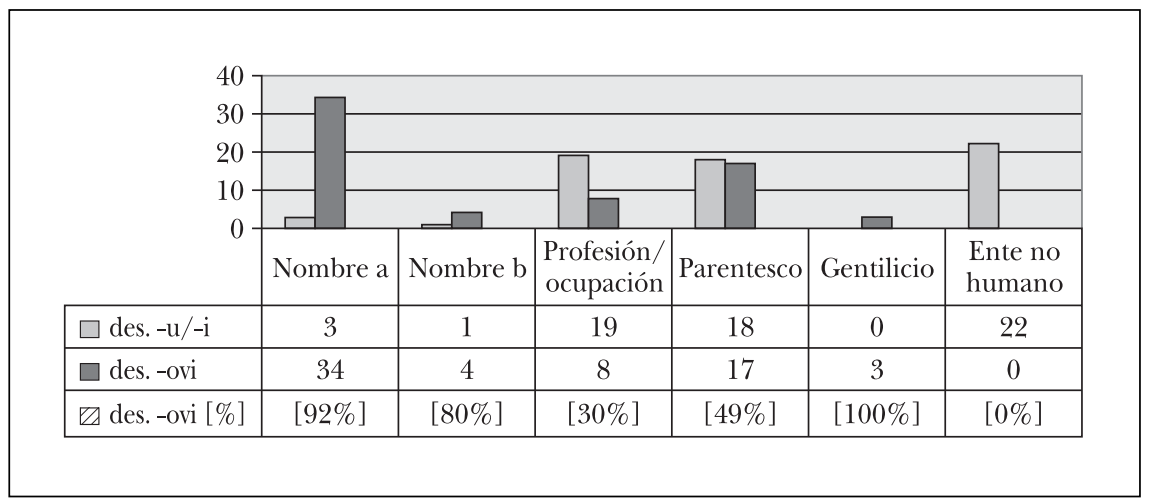

TABLA 6b: Desinencias de dativo (La abuela).

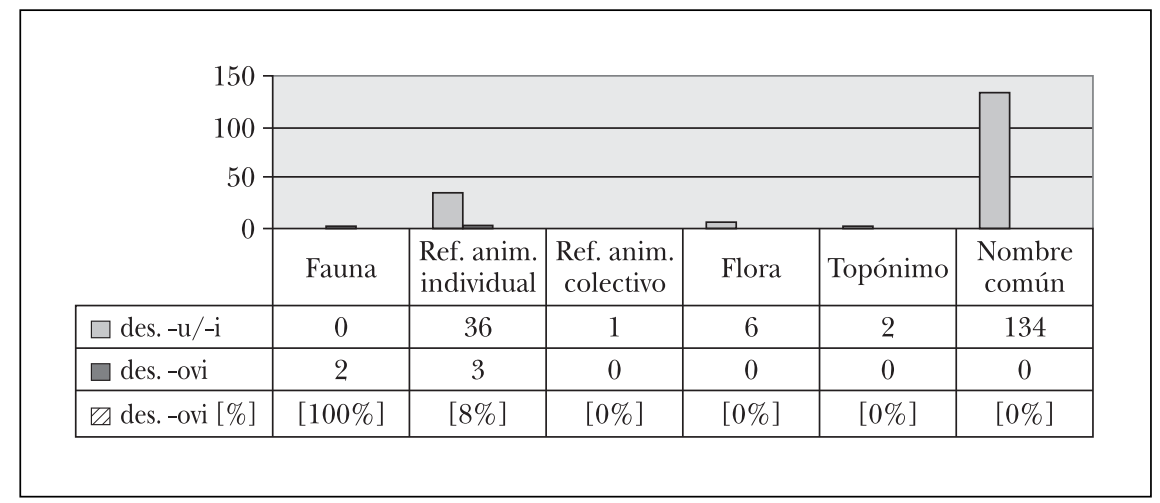


Una primera conclusión a la que podemos llegar con tan solo echar una ojeada a las tablas 6 a y 6 b es la mayor irregularidad de la distribución de las desinencias -ovi y $-u$ respecto a lo visto para los Evangelios de la Biblia de Kralice. En La abuela se documenta la desinencia -ovi en seis de las once categorías de la escala de animación, frente a las apenas tres de la Biblia de Kralice. Sin embargo, la estructura básica que esperábamos se mantiene, es decir, una alta frecuencia entre los peldaños más elevados de la escala -y muy especialmente entre los nombres propiosy una absoluta ausencia de la desinencia -ovi en la parte inferior de la escala y, más concretamente, entre las tres casillas que cierran la pirámide y que representan a los sustantivos inanimados.

Comenzaremos el estudio pormenorizado de los resultados por el peldaño más alto de la escala de animación. No resulta sorprendente el $92 \%$ de frecuencia de los sustantivos pertenecientes a lo que hemos denominado «Nombre propio a», es decir, de los nombres propios de persona. También entendemos como lógico el $80 \%$ entre los sustantivos de la clase «Nombre propio b», es decir, el de animales, al corresponderse con un grado muy alto en la frecuencia pero sustancialmente menor que en el de los nombres propios del primer tipo.

De los tres casos documentados de sustantivos que pertenecen a la categoría «Nombre propio de persona» y, sin embargo, presentan la desinencia no marcada, dos de ellos responden a un mismo nombre svatý Mikuláš 'san Nicolás'. Gebauer 1960 afirmaba en su gramática que los nombres de santos presentan la desinencia -ovi con menor frecuencia que el resto de los sustantivos animados, con lo que queda justificado sobradamente el uso de la desinencia $-u$ en estos sustantivos por parte de Němcová. El tercer ejemplo corresponde al sustantivo Václav 'Wenceslao', que es el nombre de pila de un cochero y que, por lo visto hasta aquí, no es fácilmente justificable y parece deberse a la falta de una norma estricta en el tiempo de la redacción de La abuela. En cualquier caso, no hay que olvidar que, al menos en principio, en estos supuestos el hablante tiene libertad para escoger entre la desinencia más marcada (-ovi) y la menos marcada $(-u)$, si bien, al escoger precisamente la desinencia - $u$ en lugar de -ovi para un nombre propio de persona, Němcová está marcando ese sustantivo frente al resto de su clase.

Algo muy similar encontramos con los nombres propios de animal. El nombre de uno de los perros que pertenecen a la familia, Hektor, aparece en dos ocasiones, una como Hektorovi y una segunda como Hektoru. Consideramos que el hecho de tratarse del nombre de un animal y no del de una persona puede ser el condicionante de este relativamente alto porcentaje con desinencia $-u(20 \%)$. Resulta reseñable, en cualquier caso, que los dos ejemplos documentados con $-u$ en esta primera clase estén precedidos de una preposición de dativo $k$ 'hacia'. Aun así -y dado que no hemos encontrado en ninguna publicación referencia alguna a 
esta posibilidad- no nos atrevemos a asegurar que exista una relación directa entre la presencia de una preposición de dativo y una mayor frecuencia de la desinencia $-u$, lo que además parece quedar contradicho por la presencia de un número significativo de contraejemplos.

Por otra parte, resulta sorprendente el $100 \%$ en la frecuencia de la desinencia -ovi tanto en Gentilicio como en Fauna, frente a los porcentajes notoriamente inferiores de los sustantivos que pertenecen a Profesión/ocupación (30\%) y Parentesco (49\%). Algunos de los sustantivos ubicados en estos grupos responden a una norma clara, como los sustantivos masculinos acabados en - $a$ que, como señala Gebauer 1960 en su gramática, siempre presentan la desinencia -ovi. El resto de los sustantivos se debaten entre las dos desinencias, si bien una mayoría se decide por la menos marcada. El por qué de la presencia de $-u /-i$ frente a -ovi no resulta sencillo de aclarar, si bien es digno de mención que más de dos tercios de los sustantivos que pertenecen a estas cuatro categorías de la pirámide de animación y que se documentan en más de una ocasión en el texto presentan siempre la misma desinencia, o bien $-u /-i$, o bien -ovi.

Según estos datos, concluimos que, al menos en la obra La abuela, existe una tendencia a que los sustantivos animados que no pertenecen a la clase semántica «Nombre propio» presenten una doble posibilidad desinencial, pero que ésta vendrá en gran medida condicionada por la propia configuración de la palabra y no tanto por el contexto en que ésta se encuentre. Esta afirmación viene en gran medida respaldada por los porcentajes obtenidos para la clase «Ente no humano». En todas las gramáticas, incluida la de Gebauer 1960, se especifican algunos sustantivos de carácter religioso que no pueden presentar la desinencia -ovi o que la presentan muy raramente. En La abuela se documentan hasta un total de 22 ejemplos de dativo singular con palabras del grupo semántico «Ente no humano» y que se refieren todas ellas a sustantivos de carácter religioso, sin que se documente entre ellos una única desinencia-ovi.

En cualquier caso, para la mayoría de estos sustantivos, la presencia de la desinencia -ovi o $-u /-i$ se trataría de una tendencia y no de una norma fija, como evidencia el sustantivo otec 'padre', que muestra una clara tendencia en el texto a ser usado en combinación con la desinencia $-i$ (en más del $92 \%$ de los ejemplos), pero que no es absoluta, pues se documenta una forma otcovi.

Otro factor que indudablemente juega un papel relevante respecto a la tendencia de un determinado sustantivo a tomar una desinencia más o menos marcada es, precisamente, como podemos leer en la gramática de Zikmund 1874, pp. 35-36, si la desinencia en cuestión es $-u$ o $-i$, es decir, si se trata de una palabra que termina en consonante dura o blanda. Hemos analizado las frecuencias de estas desinencias por separado en los cuatro grupos a los que hacíamos referencia con anterioridad: «Profesión/ocupación», «Parentesco», «Gentilicio»y «Fauna». Los 
resultados obtenidos para la desinencia - $i$ respecto a -ovi son de algo menos del 82\% (7/31), mientras que para la desinencia $-u$ alcanzamos apenas un $24 \%$ (19/6), lo que implica un $76 \%$ en la frecuencia de la desinencia -ovi para estos sustantivos.

Lo que no parece tener relevancia es la cuestión de los sustantivos con y sin complementos, de modo que los nombres propios de persona se documentan con la desinencia -ovi, mientras que el resto de sustantivos presentan la desinencia $-u /-i$.

El escaso $8 \%$ en la clase «Referente animado individual», unido al $0 \%$ en «Referente animado colectivo», muestra con claridad que la semántica de estas palabras apenas es compatible con la desinencia -ovi.

Por todo lo visto hasta ahora, consideramos que es posible afirmar que existe una tendencia muy fuerte a marcar con la desinencia -ovi aquellos sustantivos animados que se encuentran en la escala más alta de la pirámide, es decir, los nombres propios, sean éstos o no de persona. A partir de aquí, los sustantivos animados -a excepción de algunos pocos casos recogidos en los manuales y gramáticas- pueden optar libremente por una de las dos desinencias, - ovi o $-u /-i$. Sin embargo, no parece que se trate tanto de una elección condicionada por el contexto en el interior de la oración o por la voluntad del hablante, sino que más bien algunos sustantivos animados presentan una mayor tendencia a declinarse con -ovi y otros con $-u /-i$.

Existiría, por lo tanto, una doble perspectiva para explicar la mayor o menor tendencia a presentar la desinencia de dativo -ovi. Por una parte, una cuestión fonotáctica, de modo que los sustantivos acabados en consonante blanda tienen una menor tendencia a presentar la desinencia-ovi que los acabados en consonante dura. El segundo factor responde a cuestiones semánticas, ya que los sustantivos cuya semántica esté relacionada con la religión, al igual que las palabras cuya semántica sea animada pero abstracta -los referentes animados individuales y colectivos- tienen una marcada tendencia a no presentar nunca la desinencia -ovi.

Por último, el hablante entiende los sustantivos pertenecientes a los grupos semánticos «Flora», «Topónimo»y «Nombre común» como inanimados y, por tanto, no los marca jamás con la desinencia de dativo singular -ovi.

A mediados del siglo XIX nos encontramos una situación compleja, difícilmente reducible a reglas claras y que deja a la intuición del hablante la responsabilidad en el uso de una u otra desinencia, si bien de acuerdo con unas tendencias claras y marcadas, según nuestro parecer, por la tradición. La única norma taxativa se refiere a la imposibilidad absoluta respecto a la presencia de la desinencia -ovi con los sustantivos inanimados, lo que en periodos anteriores del desarrollo de la lengua checa -y como viéramos para el checo antiguo- era tan solo una tendencia, si bien muy marcada. 


\section{ESTUdIO SEMÁNTICO-MORFOLÓGICO EN EL CHECO CONTEMPORÁNEO (TRENES RIGUROSAMENTE VIGILADOS DE BOHUMIL HRABAL)}

Tras el estudio de las distintas etapas del desarrollo histórico de la lengua checa hemos alcanzado el último estadio, el denominado checo contemporáneo. En cuanto a la obra concreta con la que trabajar, nos decidimos por Trenes rigurosamente vigilados porque se trata de una de las novelas más destacadas de uno de los escritores contemporáneos más reconocidos en lengua checa, Bohumil Hrabal (1914-1997). En el texto se ha documentado un total de 57 entradas de las cuales 37 presentan la desinencia $-u /-i[65 \%$ ] y 20 la desinencia - ovi $[35 \%]$.

TABLA 7a: Desinencias de dativo (Trenes rigurosamente vigilados).

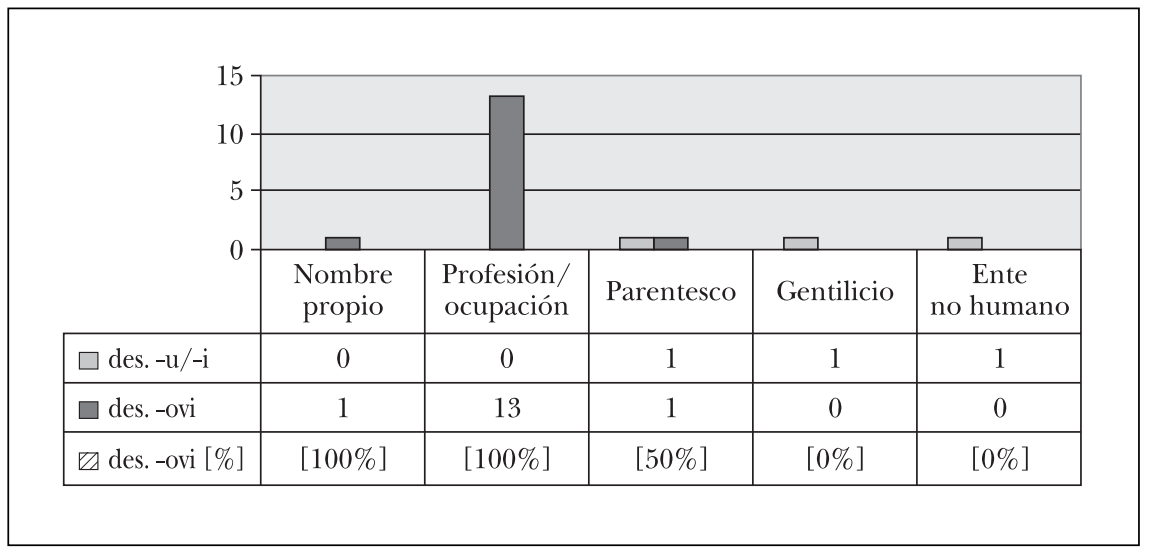

TABLA 7b: Desinencias de dativo (Trenes rigurosamente vigilados).

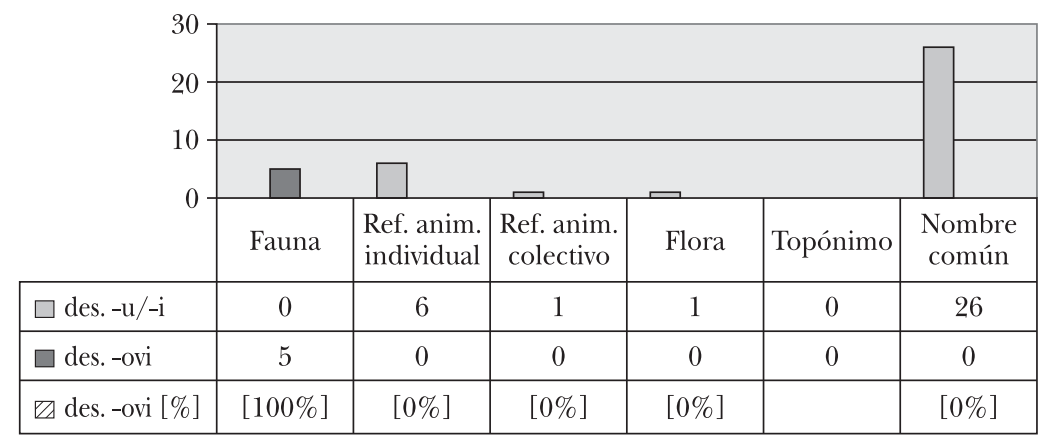


Al revisar los datos obtenidos en el análisis de las desinencias de dativo singular de Trenes rigurosamente vigilados no encontramos ninguna sorpresa. Observamos unos porcentajes muy elevados para las categorías «Nombre propio de persona», «Profesión/ocupación» y «Fauna», unos porcentajes muy bajos -en este caso concreto del $0 \%$, si bien posiblemente a causa del escaso número de datos que nos aporta este texto- en «Ente no humano», «Referente animado individual» y «Referente animado colectivo»y, por último, un esperado y evidente $0 \%$ en la frecuencia de la presencia de la desinencia -ovi en los sustantivos inanimados.

Sin embargo, observamos que de los 23 sustantivos que se documentan para las seis primeras categorías de la pirámide de animación, todos los sustantivos que tienen terminación en consonante blanda presentan la forma $-i$, mientras que todos los que la tienen en consonante dura o en - $a$ se documentan con la desinencia -ovi, incluidas las cinco entradas para nombres de animales. Esto corroboraría la observación de Rusínová en Karlík, Nekula y Rusínová 1995, p. 247, que defiende que, a falta de complementos, las palabras masculinas acabadas en consonante blanda nunca toman la desinencia -ovi y contradice aprentemente lo expuesto en los capítulos de morfología nominal de algunas gramáticas clásicas de prestigio como Trávníček 1951, pp. 457-460, que afirman que la desinencia de dativo entre los sustantivos del paradigma palatal puede ser tanto $-i$ como $-o v i^{12}$.

Por tanto, nos interesaría demostrar si en el checo contemporáneo, y tal como parecen apuntar los datos extraídos del análisis de Trenes rigurosamente vigilados, no se emplea la desinencia -ovi tras los sustantivos animados que terminan en consonante palatal ${ }^{13}$. Para comprobarlo hemos hecho un breve pero significativo análisis a través del programa SYN2000 que pertenece al Český národní korpus ('Corpus nacional checo') y que acumula 100 millones de palabras pertenecientes a publicaciones aparecidas entre 1990 y $1999^{14}$.

Los datos son contundentes en este sentido, con un total de 1.850 entradas y tan solo dos ejemplos en -ovi (apenas el 0,11\%) ${ }^{15}$ :

12 A este respecto parece bastante esclarecedora la opinión de Osolsobě 2002, p. 336, quien afirma que la información que aparece en las gramáticas de lengua checa en relación a las desinencias de dativo singular es vaga e insuficiente.

${ }^{13}$ Quiero agradecer al Dr. Hermida de Blas por sus apreciaciones a este respecto durante la defensa de mi tesis doctoral.

${ }^{14}$ La composición de estos textos es la siguiente: publicaciones periódicas genéricas $60 \%$, publicaciones especializadas $25 \%$ y literatura $15 \%$. Más información en la página web $<$ http://ucnk.ff.cuni.cz/>.

${ }_{15}$ Para asegurarnos de que se trataban de formas de dativo y no de otras posibles formas acabadas en -ovi (especialmente de locativo) estas cifras se refieren exclusivamente a sustantivos precedidos por una palabra acabada en - $m u$, que puede tratarse tanto de un adjetivo como de un determinante. 


\begin{tabular}{|l|c|c|c|c|c|c|}
\hline & $\begin{array}{c}\text { Otec } \\
\text { 'Padre' }\end{array}$ & $\begin{array}{c}\text { Lékaŕ } \\
\text { 'Médico' }\end{array}$ & $\begin{array}{c}\text { Král } \\
\text { 'Rey' }\end{array}$ & $\begin{array}{c}\text { Knĕz } \\
\text { 'Príncipe' }\end{array}$ & $\begin{array}{c}\text { Muž } \\
\text { 'Hombre' }\end{array}$ & $\begin{array}{c}\text { Přitel } \\
\text { 'Amigo' }\end{array}$ \\
\hline Des. $-i$ & 349 & 271 & 174 & 24 & 711 & 321 \\
\hline Des. -ovi & 1 & 0 & 1 & 0 & 0 & 0 \\
\hline
\end{tabular}

Estos datos se refieren exclusivamente a los nombres comunes animados, pues entre los nombres propios con desinencia palatal sí encontramos la doble posibilidad -ovi/-i activa: Miloši (3) frente a Milošovi (1), Tomáši (9) frente a Tomášovi (4) o Mikuláši (4) frente a Mikulášovi (1) lo que significa un nada despreciable $27 \%$ del total.

Un análisis similar de los sustantivos no palatales muestra una tendencia mucho más acorde con la doble posibilidad, con 161 entradas con desinencia $-u(15 \%)$ frente a 916 en -ovi $(85 \%)$ de un total de 1.077 :

\begin{tabular}{|l|c|c|c|c|c|c|}
\hline & $\begin{array}{c}\text { Prezident } \\
\text { 'Presidente' }\end{array}$ & $\begin{array}{c}\text { Syn } \\
\text { 'Hijo' }\end{array}$ & $\begin{array}{c}\text { Kamarád } \\
\text { 'Amigo' }\end{array}$ & $\begin{array}{c}\text { Čech } \\
\text { 'Checo' }\end{array}$ & $\begin{array}{c}\text { Soused } \\
\text { 'Vecino' }\end{array}$ & $\begin{array}{c}\text { Vnuk } \\
\text { 'Nieto' }\end{array}$ \\
\hline Des. $-u$ & 97 & 49 & 12 & 1 & 2 & 0 \\
\hline Des. -ovi & 447 & 280 & 68 & 15 & 83 & 23 \\
\hline
\end{tabular}

Otros datos interesantes que extraemos del análisis del corpus SYN2000 es la preponderancia absoluta de la forma de dativo singular bohu sobre bohovi (130/1) «Dios», que contrasta con la relativa igualdad de Kristovi frente a Kristu (2/3) «Cristo». En cuanto a los nombres de santos, resulta difícil, si no imposible, averiguar con ayuda de estas muestras poco representativas mediante el análisis del SYN2000 si el carácter sagrado de estos sustantivos tiene alguna clase de influencia sobre la elección del hablante. Nos decantamos por el la respuesta negativa, puesto que entre los nombres de santos que terminan en consonante palatal se repiten exactamente los mismos porcentajes que para los nombres propios que no van antecedidos del adjetivo svatému 'santo': once sustantivos en $-i(73 \%)$ frente a cuatro en -ovi $(27 \%)$.

Tras el análisis de los datos -que en el caso de los obtenidos mediante el SYN2000 son meramente aproximativos, dado el carácter arbitrario en su elección- cabría asegurar que el sistema en checo contemporáneo ha alcanzado un grado muy alto de estabilidad, es decir, que a pesar de que las dos posibilidades desinenciales $-o v i \mathrm{y}-u /-i$ se consideren gramaticales para la inmensa mayoría de los supuestos, a la hora de la verdad existe una tradición muy asentada que sirve de norma y que determina 
cuándo se ha de usar - ovi y cuándo - $u$ o- $i$, de modo que esta libertad de elección desaparece en lo relativo a los sustantivos masculinos que terminan en $-a$ (siempre desinencia -ovi) y cuando se trata de nombres comunes terminados en consonante palatal (siempre desinencia-i). Es decir, que a pesar de lo que señala un gran número de gramáticas y manuales de la lengua checa, no existe una capacidad real del hablante para escoger la desinencia de un sustantivo común masculino terminado en consonante palatal, puesto que éste escoge casi de forma exclusiva, al menos en el lenguaje escrito, la desinencia -i. Aun así, la semántica del sustantivo puede jugar un papel relevante, como puede observarse en los nombres propios de persona, que sí tienen cierta tendencia a presentar la desinencia-ovi y, por tanto, donde existe una doble posibilidad -ovi/-i.

Es cierto que para poder determinar la dimensión real de esa capacidad de elección por parte del hablante haría falta un trabajo de análisis de textos enormemente mayor al que aquí se recoge, lo que escapa a las dimensiones preeminentemente diacrónicas de la investigación.

\section{Conclusiones}

Este último apartado recoge brevemente las conclusiones finales obtenidas como fruto del análisis semántico-morfológico del dativo en antiguo eslavo y en checo que hemos realizado a lo largo de nuestra investigación.

La primera conclusión que se puede extraer del análisis del Codex Marianus es que en antiguo eslavo existe una clara tendencia a que los sustantivos de tema en $-\breve{u}$ presenten con mucha mayor frecuencia la desinencia -окн (-ovi) que aquellos otros sustantivos que pertenecen etimológicamente a los temas temáticos. Por el contrario, el análisis ha demostrado que en ninguna etapa histórica de la lengua checa, ni siquiera en los primeros textos en checo antiguo, continúa vigente la diferencia formal en dativo entre los sustantivos de los temas temáticos y en $-\breve{u}$.

En lo tocante a la validez de la jerarquía de animación respecto a la presencia o ausencia de la desinencia -ovi, semejante a la demostrada ya por Huntley 1993 para el sincretismo genitivo-acusativo, los resultados del análisis del Codex Marianus confirman dicha hipótesis con claridad. Si bien la pirámide de animación de las desinencias de dativo no es una escala absoluta, muestra una tendencia clara a que a mayor grado de animación de los sustantivos, mayor sea la frecuencia con que se documenten con la desinencia -оKH (-ovi).

En lo que respecta al primer estadio de la lengua checa histórica, el checo antiguo, observamos que en el Manuscrito de Viena -el más relevante de nuestro estudio de la Crónica de Dalimil- existe, efectivamente, una jerarquía de animación entre los dos primeros escalones, «Nombre 
propio de persona» $(68 \%)$ y «Profesión/ocupación» $(27 \%)$, mientras que para el resto de las clases no se documenta ni un único sustantivo con desinencia -ovi. Respecto a las cifras que obtuvimos para el Codex Marianus se distingue, sin embargo, una tendencia ya evidente en checo antiguo a marcar aún más con la desinencia -ovi los nombres propios de persona al tiempo que, por el contrario, se marca con menor frecuencia los pertenecientes a «Profesión/ocupación». La tendencia aquí expuesta y que parece apuntar hacia una mayor estabilidad del sistema, es incluso más intensa al alejarnos del manuscrito original, es decir, al observar la suma de los resultados de todos los manuscritos conservados. Además, ninguna de las fuentes analizadas rompe esta tendencia. Esta evidente jerarquía de animación apreciable en todos los manuscritos se ve distorsionada por un mínimo porcentaje de sustantivos que sí presentan las desinencia -ovi, pero que no pertenecen a los dos primeros escalones de la jerarquía de animación.

En el segundo estadio de nuestro análisis diacrónico de la lengua checa, que venía representado por los Evangelios de la Biblia de Kralice, no se documenta ya una pirámide jerárquica como la atestiguada en antiguo eslavo y en checo antiguo, sino una norma clara que parece la culminación de la tendencia observable ya en checo antiguo a marcar con la desinencia -ovi exclusivamente el primer peldaño de la jerarquía de animación. Así, en los Evangelios de la Biblia de Kralice todos los nombres propios de persona masculinos presentarían la desinencia -ovi y todos los demás sustantivos masculinos, tanto animados como inanimados, harían el dativo singular en - $u$. La única excepción vendría representada por un cierto número de sustantivos animados que acaban en consonantes velares $(k, c h, h, g)$. En cualquier caso, no se trata de una norma clara, pues la gran mayoría de estos sustantivos animados no se documenta con la desinencia -ovi.

El penúltimo estadio de nuestra investigación viene representado por la novela La abuela de Božena Němcová y los resultados del análisis muestran un evidente paso atrás en el proceso normalizador pretendido por los autores de la Biblia de Kralice, que se refleja en una mayor irregularidad en la distribución de las desinencias -ovi y - $u$. Aun así, la estructura básica que esperábamos se mantiene, es decir, una alta frecuencia de la desinencia -ovi entre los peldaños más elevados de la escala -y muy especialmente entre los de la clase «Nombres propio»- y su ausencia absoluta en la parte inferior de la escala.

No resulta sencillo aclarar el por qué de la irregular presencia de la desinencia -ovi frente a $-u /-i$ en las clases «Profesión/ocupación» $(30 \%)$, «Parentesco» $(49 \%)$, «Gentilicio» (100\%), «Ente no humano» $(0 \%)$, «Fauna» $(100 \%)$, «Referente animado individual» $(8 \%)$ y «Referente animado colectivo» $(0 \%)$. Generalmente se habla de que -con la excepción de algunos pocos casos recogidos en los manuales y gramá- 
ticas- los hablantes pueden optar libremente por cualquiera de las dos desinencias de dativo (-ovi o $-u /-i)$. Sin embargo, el análisis de los datos apunta en otra dirección, de modo que no parece tratarse tanto de una elección condicionada por el contexto en el interior de la oración o por la voluntad del hablante, sino que más bien algunos sustantivos animados presentan una mayor tendencia a declinarse con -ovi y otros con $-u /-i$. Esto vendría a explicar por qué la inmensa mayoría de los sustantivos que pertenecen a estas siete categorías de la pirámide de animación y que se documentan en más de una ocasión en el texto presentan siempre la misma desinencia, bien $-u /-i$, bien $-o v i$.

$\mathrm{Al}$ revisar los datos obtenidos en el análisis de las desinencias de dativo singular del texto que representa el último periodo de nuestro estudio diacrónico de la lengua checa, Trenes rigurosamente vigilados, observamos que de los 23 sustantivos que se documentan para las seis primeras categorías de la pirámide de animación, todos los sustantivos que tienen terminación en consonante blanda presentan la forma $-i$, mientras que todos los que la tienen en consonante dura o en - $a$ se documentan con la desinencia -ovi, incluidas las cinco entradas para nombres de animales. Esto parece indicar que los sustantivos comunes acabados en consonante blanda nunca toman la desinencia -ovi. El análisis de los datos documentados en el corpus SYN2000 -a pesar del valor aproximativo de sus conclusiones dado el carácter arbitrario en su elección y de tratarse exclusivamente de sustantivos acompañados de complementos- parece confirmar esta hipótesis, de modo que no existe una capacidad real del hablante para escoger la desinencia de un sustantivo común masculino terminado en consonante palatal ya que, a pesar de lo que señalan generalmente gramáticas y manuales de la lengua checa, prima con claridad el uso de la desinencia $-i$ sobre la desinencia -ovi.

El sistema de desinencias de dativo singular masculino en checo contemporáneo es, en cualquier caso, un sistema relativamente abierto, falto de la heterogeneidad y la lógica que intentara inculcarle mediante su esfuerzo normalizador Jan Blahoslav en la segunda mitad del siglo XVI. Sin embargo, la sensación que nos queda es la de un sistema mucho más regularizado que el de la novela $L a$ abuela, donde algunas elecciones de la autora respecto a las desinencias de dativo singular resultarían difíciles de justificar en checo contemporáneo a la vista de los datos que hemos obtenido para Trenes rigurosamente vigilados y para el corpus SYN2000.

\section{REFERENCIAS BIBLIOGRÁFICAS}

DAŇHelKa, J.; HÁDEK, K.; HaVRÁNeK, B. y KvítKová, N. (1988a): Staročeská kronika tak rečeného Dalimila. Vydání textu a veškerého textového materiálu. Svazek 1. Úvod. Text kroniky v základním rukopise. Textový materiál předmluvy a kapitol 1 až 52, Praga, Academie. 
—, (1988b): Staročeská kronika tak řečeného Dalimila. Vydáni textu a veškerého textového materiálu. Svazek 2. Textový materiál kapitol 53 až 103 a doplňků, Praga, Academie.

GARDINER, S. C. (1984): Old Church Slavonic: an elementary grammar, Cambridge, Cambridge University Press.

Gebauer, J. (1960): Historická mluvnice jazyka českého. Díl III. Tvarosloví. I. Skloňování, Praga, Nakladatelství československé akademie věd [1ํㅡㄹ edición 1896].

GutiérRez Rubio, E. (2004): «Datividad y animación en los Evangelios de la Biblia de Kralice», Eslavística Complutense 4, pp. 189-200.

Hrabal, B. (2002): Ostře sledované vlaky, Praga, nakladatelství Mat'a.

HradiL, I. y JirečEK, J. (ed.) (1857): Grammatika česká Jana Blahoslava, Viena.

HroznÝ, J. (ed.) (1913): Bible Kralická k tristaleté památce, Praga, Nakladatelství J. Otto Spol. s R.O.

Huntley, D. (1993): «Old Church Slavonic» en Comrie, B. y Corbett, G. G. (ed.), The Slavonic Languages, Londres, Roudledge, pp. 125-187.

IgARTUA, I. (2005): Origen y evolución de la flexión nominal eslava, Bilbao, Servicio Editorial. Universidad del País Vasco.

JaGIČ, V. (ed.) (1883): Codex Marianus glagoliticus, Санктпетербургь, типографія императорской академіи наукь.

JANDA, L. A. (1996): «Figure, ground, and animacy in Slavic declesion», The Slavic and East European Journal 40, 2, pp. 325-355.

Karlík, P.; Nekula, M. y Rusínová, Z. (ed.) (1995): Příruční mluvnice češtiny, Praga, Nakladatelství Lidové Noviny.

NĚMCOvÁ, B. (2001): Babička. Obrazy z venkovského života, Reprint vydání z roku 1942, Praga, Nakladatelství Levné knihy KMa.

OsOLSOBĚ, K. (2002): «Mluvnice versus korpus. Několik poznámek k problémům dubletních a variantních koncovek českých substantiv», en Hladká, Z. y Karlík, P. (ed.), Čeština. Univerzália a specifika 4, Praga, Nakladatelství Lidové Noviny, pp. 333-336.

TrÁvNíčEK, F. (1951): Mluvnice spisovné češtiny. Část I. Hláskoslovi - Tvoření slov Tvarosloví, Praga, Slovanské Nakladatelství.

VÁŽNÝ, V. (1964): Historická mluvnice česká II. Tvarosloví. 1. část. Skloňování, Praga, Státní pedagogické nakladatelství.

ZIKMUnd, V. (1874): Mluvnice jayzka českého: pro nižši tř́dy střednich škol, 2ª ed., Praga, nákladem kněhkupectví I. L. Kober.

\section{Páginas web consultadas}

Bible kralická: <http://www.etf.cuni.cz/ rovnanim/bible/k/Mt1.php>

Český národní korpus: <http://ucnk.ff.cuni.cz/>

Codex Marianus: <http://www.helsinki.fi/slaavilaiset/ccmh/marianus.html>

$<$ http://ucnk.ff.cuni.cz/>

$<$ http://www.etf.cuni.cz/ rovnanim/bible/k/Mt1.php $>$

$<$ http://www.slav.helsinki.fi/ccmh/MAR.TXT> 